\title{
Solution probing of metal ion binding by helix 27 from Escherichia coli 165 rRNA
}

\author{
MEREDITH NEWBY LAMBERT, JOHN A.H. HOERTER, MIGUEL J.B. PEREIRA, and NILS G. WALTER
}

Department of Chemistry, University of Michigan, Ann Arbor, Michigan 48109-1055, USA

\begin{abstract}
Helix (H)27 from Escherichia coli 16S ribosomal (r)RNA is centrally located within the small (30S) ribosomal subunit, immediately adjacent to the decoding center. Bacterial $30 \mathrm{~S}$ subunit crystal structures depicting $\mathrm{Mg}^{2+}$ binding sites resolve two magnesium ions within the vicinity of $\mathrm{H} 27$ : one in the major groove of the G886-U911 wobble pair, and one within the GCAA tetraloop. Binding of such metal cations is generally thought to be crucial for RNA folding and function. To ask how metal ion-RNA interactions in crystals compare with those in solution, we have characterized, using solution NMR spectroscopy, $\mathrm{Tb}^{3+}$ footprinting and time-resolved fluorescence resonance energy transfer (tr-FRET), location, and modes of metal ion binding in an isolated H27. NMR and $\mathrm{Tb}^{3+}$ footprinting data indicate that solution secondary structure and $\mathrm{Mg}^{2+}$ binding are generally consistent with the ribosomal crystal structures. However, our analyses also suggest that $\mathrm{H} 27$ is dynamic in solution and that metal ions localize within the narrow major groove formed by the juxtaposition of the loop E motif with the tandem G894-U905 and G895-U904 wobble pairs. In addition, tr-FRET studies provide evidence that $\mathrm{Mg}^{2+}$ uptake by the $\mathrm{H} 27$ construct results in a global lengthening of the helix. We propose that only a subset of $\mathrm{H} 27-$ metal ion interactions has been captured in the crystal structures of the $30 \mathrm{~S}$ ribosomal subunit, and that small-scale structural dynamics afforded by solution conditions may contribute to these differences. Our studies thus highlight an example for differences between RNA-metal ion interactions observed in solution and in crystals.
\end{abstract}

Keywords: metal ion binding; NMR spectroscopy; terbium footprinting; time-resolved fluorescence resonance energy transfer (tr-FRET)

\section{INTRODUCTION}

As the most abundant cellular divalent metal ion, $\mathrm{Mg}^{2+}$ is thought to be crucial to RNA function by promoting folding through a reduction of the electrostatic repulsion between the negatively charged backbone phosphates. RNA electrostatic potential and ion distribution calculations in combination with spectroscopic and thermodynamic measurements have led to our current understanding that a majority of $\mathrm{Mg}^{2+}$ ions at physiologic (millimolar) concentrations readily traverse the solvent-accessible surface of an RNA and move from one negative potential sink to the next on the millisecond timescale (Manning 1978; Draper 2004; Draper et al. 2005; Woodson 2005). Any RNA dynamics will be linked to rearrangements of this diffusely bound, fully hydrated cation cloud around the RNA and vice versa. Occasionally, $\mathrm{a} \mathrm{Mg}^{2+}$ ion may site-specifically reside in a region of particularly high

Reprint requests to: Nils G. Walter, Department of Chemistry, University of Michigan, 930 N. University, Ann Arbor, MI 48109-1055, USA; e-mail: nwalter@umich.edu; fax: (734)647-4865.

Article and publication are at http://www.rnajournal.org/cgi/doi/ 10.1261/rna.2940705. electronegative surface potential, such as close to phosphates partially buried within a tightly folded RNA; however, the energetic penalty for partial dehydration must be overcome to form an innersphere coordinated metal-RNA chelate (Draper 2004; Draper et al. 2005). Recent advances in X-ray crystallography have yielded many insightful RNA crystal structures, which often depict metal ions bound in specific sites. Relatively little is known, however, about how such seemingly stable metal ion binding sites in the frozen solid state of a crystal compare with metal ion binding properties in solution (Hermann and Westhof 1998; Wedekind and McKay 2003; Draper 2004; Draper et al. 2005; Woodson 2005).

Helix $(\mathrm{H}) 27$ is located within the decoding region of $16 \mathrm{~S}$ ribosomal (r) RNA from Escherichia coli (Fig. 1A; Wimberly et al. 2000). Cryo-electron microscopy studies have indicated that relative ratcheting motions of the $30 \mathrm{~S}$ and $50 \mathrm{~S}$ ribosomal subunits during translocation are centered around H27 (Tama et al. 2003), which serves as an intersubunit bridge in a very dynamic region of the ribosome (Peske et al. 2004). In 1997 Lodmell and Dahlberg proposed that the $\mathrm{H} 27$ stem-loop is dynamic and alternates between two plausible base-pairing patterns (Fig. 1B), the 


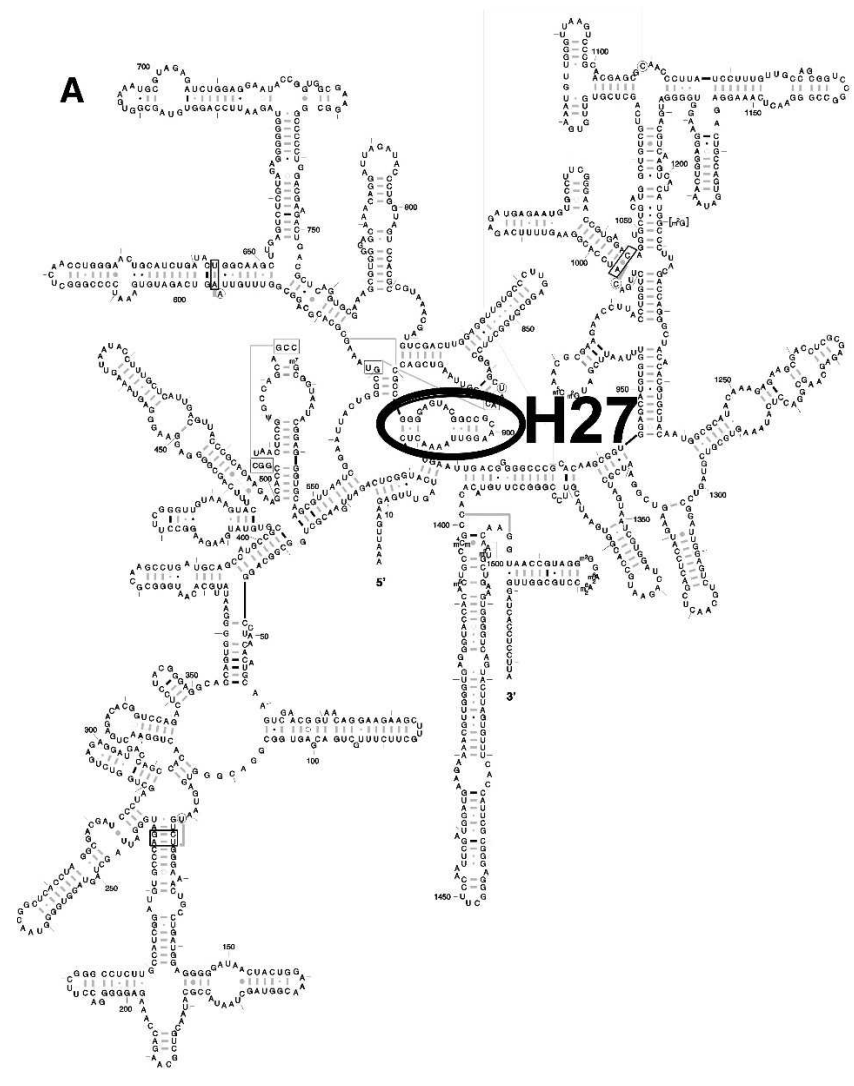

B

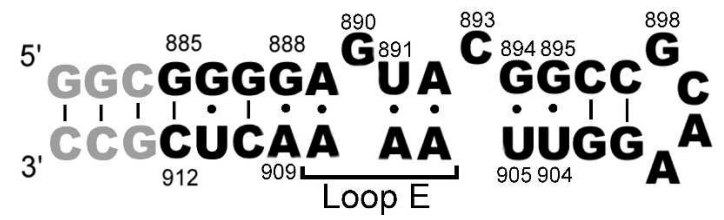

FIGURE 1. Helix 27 is centrally located within 16S rRNA. (A) Secondary structure map of $16 \mathrm{~S}$ rRNA from E. coli (Cannone et al. 2002) with helix 27 circled. (B) Helix 27 NMR construct. The proposed 912-885 secondary structure of the helix 27 sequence is shown in black. Gray nucleotides were added to preferentially stabilize the 885 conformation for NMR study. Dashes represent canonical Watson-Crick base pairs; dots represent known non-Watson-Crick base pair interactions.

912-885 (885) and 912-888 (888) conformations, early in the translational cycle. Subsequent crystal structures of "open" and "closed" forms of the 30 S subunit in complex with aminoglycoside antibiotics consistently depict $\mathrm{H} 27$ in the 885 conformation (Ogle et al. 2002), as do crystal structures of hyperaccurate ribosomes containing S12 mutations (Vila-Sanjurjo et al. 2003). Follow-up studies by the Dahlberg group revealed that their previous findings originated from a synergistic effect between $\mathrm{H} 27$ and selective marker mutations (Rodriguez-Correa and Dahlberg 2004), suggesting that $\mathrm{H} 27$ does not need to switch between conformations during translation. In contrast, an isolated $\mathrm{H} 27$ exists in a rapid dynamic equilibrium between the 885 and 888 conformations, indicative of a low energy barrier for conformational switching (Hoerter et al. 2004). A simple extension of the terminal helix of this isolated $\mathrm{H} 27$ stabilizes the 885 conformation (Hoerter et al. 2004), making it a suitable system to probe the metal ion binding of this ribosomal structural element in solution. This is of particular interest since the 885 conformation contains a loop E motif (Fig. 1B), a common structural motif in RNA (Leontis and Westhof 1998). Bacterial 30S ribosomal subunit crystal structures depicting magnesium ion binding sites consistently place two such $\mathrm{Mg}^{2+}$ binding sites at opposite ends of H27 (Brodersen et al. 2000; Carter et al. 2000; Ogle et al. 2001, 2002): one (Mg73) adjacent to the G886-U911 pair and another one (Mg126) within the GNRA tetraloop (Fig. 1B), a common metal ion binding site (Hermann and Westhof 1998; Maderia et al. 2000; Rudisser and Tinoco 2000; Mundoma and Greenbaum 2002). The metal-RNA distances are all $>2.8 \AA$, consistent with the notion that these metal ions are outersphere (diffusely) bound. However, it is unclear whether in solution similar and/or additional sites are occupied.

To begin to probe the relationship between metal ion binding sites inferred from crystal data of $\mathrm{H} 27$ and those in solution, we have applied NMR chemical shift assays, $\mathrm{Tb}^{3+}$ footprinting, and time-resolved (tr) FRET-based distance measurements to an extended construct representing the 885 conformation of $\mathrm{H} 27$ from E. coli 16S rRNA (Fig. 1B). Our NMR and $\mathrm{Tb}^{3+}$ footprinting data verify the crystallographically observed base-pairing pattern and $\mathrm{Mg}^{2+}$ binding sites in solution (Brodersen et al. 2000; Carter et al. 2000; Ogle et al. 2001, 2002). In addition, NMR analyses point to metal ion interactions in the vicinity of the tandem G894-U905 and G895-U904 wobble pairs that are not predicted by the crystal structures, while tr-FRET measurements reveal an end-to-end distance increase in $\mathrm{H} 27$ upon association with $\mathrm{Mg}^{2+}$. We propose that only a subset of H27-metal ion interactions are described in crystal structures of the small ribosomal subunit where magnesium ion binding sites are observed, and that local dynamics on the NMR timescale afforded by solution conditions may contribute to these differences. Our studies of $\mathrm{H} 27$ highlight potential discrepancies between RNA-metal ion interactions in solution and in crystals.

\section{RESULTS}

\section{Establishment of the base-pairing pattern of the 885 conformation of $\mathrm{H} 27$ in solution}

Previous studies by our group have indicated that an isolated $\mathrm{H} 27$ exists in a rapid dynamic equilibrium between the 885 and 888 conformations, suggesting a low energy barrier to conformational switching (Hoerter et al. 2004). To stabilize a single conformation and suppress any conformational switching, we here have designed an NMR construct with three G-C (C-G) pairs added to the helix terminus that "lock" it into the 885 
conformation (Fig. 1B). To verify the predicted base-pairing pattern of the 885 conformation, NOESY spectra of exchangeable protons were collected and imino proton resonances assigned by standard strategies. In particular, we used iminoimino and imino-amino NOEs to identify sequential residues, and ${ }^{1} \mathrm{H}^{-}{ }^{15} \mathrm{~N}$ HSQC cross-peaks to unambiguously distinguish G from U imino proton resonances (Wijmenga et al. 1993; Varani et al. 1996). Figure 2 shows relevant regions of exchangeable NOESY and ${ }^{1} \mathrm{H}_{-}{ }^{15} \mathrm{~N}$ HSQC spectra, with sequential connectivities drawn and resonance assignments labeled. Assignments were initially made in $10 \mathrm{mM} \mathrm{Na}_{\mathrm{i}} \mathrm{PO}_{4}$ (pH 6.4), $0.1 \mathrm{mM} \mathrm{EDTA}$, and $50 \mathrm{mM} \mathrm{NaCl}$, in the absence of $\mathrm{Mg}^{2+}$, so that the effect of metal ions on specific resonances could subsequently be assessed.

NMR spectra of the 885 construct do not show any U NH3 imino proton resonances within the 12- to 15 -ppm WatsonCrick region (Fig. 2), consistent with the base-pairing pattern in crystal structures that is devoid of canonical A-U base pairs (Fig. 1B; Ban et al. 2000; Carter et al. 2000; Schluenzen et al. 2000; Wimberly et al. 2000; Yusupov et al. 2001). Instead, the imino proton NMR spectrum of our 885 construct displays all of the characteristics of the loop E motif, as first documented by Szewczak and Moore (1995) in the ribosomal sarcin-ricin loop. This includes a far upfield-shifted $\mathrm{NH} 1$ imino proton resonance belonging to the looped-out G890 (Fig. 2). In addition, the spectrum shows a sharply upfield-shifted G NH1 resonance at $10.6 \mathrm{ppm}$, a GNRA tetraloop hallmark, which we were able to assign to G898 (Fig. 2). Two upfield U imino proton resonances were also observed between 11.5 and $12.0 \mathrm{ppm}$ that display strong NOEs to upfield G NH1 resonances, indicative of G-U pairing. These resonances were assigned to the $\mathrm{U} \mathrm{NH} 3$ resonances within the G895-U904 and G886-U911 wobble pairs (Figs. 1B, 2). The line widths of a number of resonances throughout the molecule are broadened slightly, including G886 NH1, U911 NH3, U904 $\mathrm{NH} 3$, and G890 NH1, providing evidence for molecular motion near the G-U wobble pairs and the looped-out base. Nevertheless, the assignable number of imino proton resonances in Figure 2, together with the high resolution of the spectrum, indicates that the 885 construct forms a single, welldefined hairpin. This hairpin contains key features of the loop E motif, namely, a non-Watson-Crick paired G within the helix and at least two G-U pairs as evidenced by NOESY spectra of exchangeable protons. Therefore, it most likely assumes the conformation observed for $\mathrm{H} 27$ in crystal structures of the $30 \mathrm{~S}$ subunit and the intact ribosome, as expected (Ban et al. 2000; Carter et al. 2000; Schluenzen et al. 2000; Wimberly et al. 2000; Yusupov et al. 2001).

\section{NMR-based detection of local cobalt(III) hexammine and $\mathrm{Mg}^{2+}$ binding by the 885 conformation}

To begin to pinpoint binding sites of multivalent metal ions in solution, we utilized cobalt(III) hexammine $\left(\mathrm{Co}\left(\mathrm{NH}_{3}\right)_{6}{ }^{3+}\right)$ as a probe for outersphere $\mathrm{Mg}^{2+}$ coordination in the 885

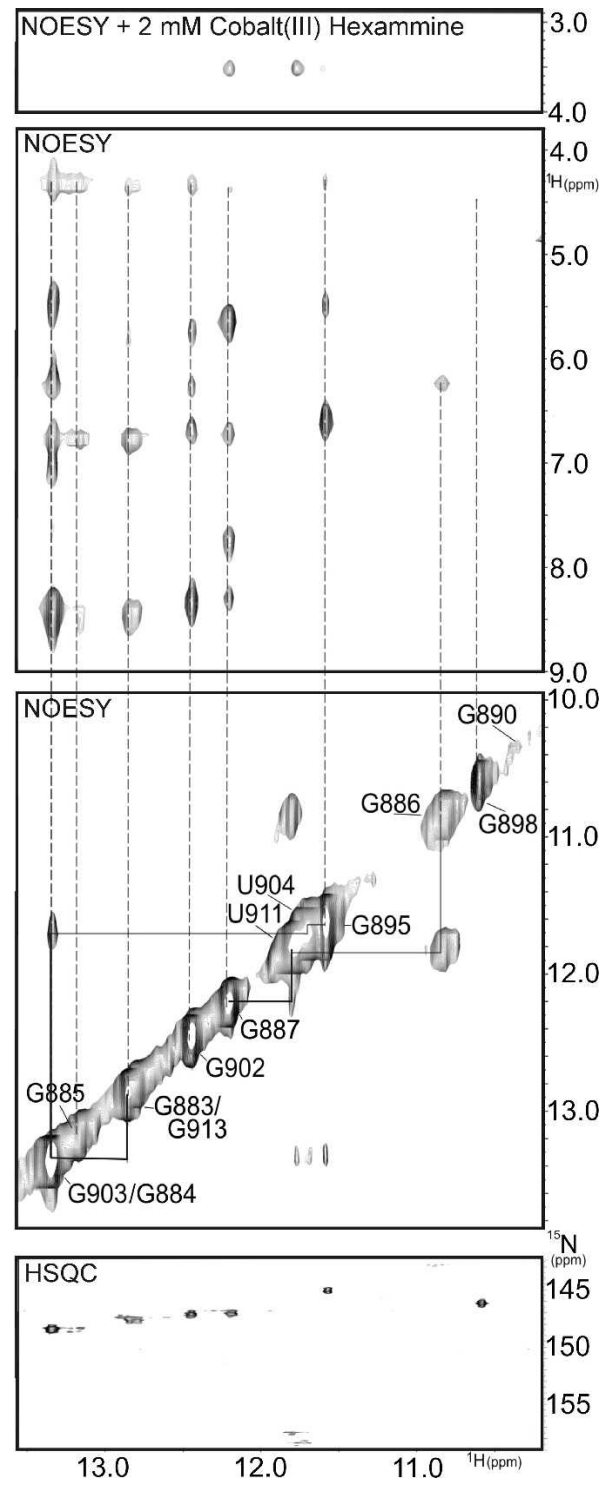

FIGURE 2. Two-dimensional NMR spectra used to assign imino proton resonances in the 885 construct. (Center two panels) Imino-amino and imino-imino regions of 150 -msec mixing time NOESY spectra of 885. Connectivities are drawn with solid lines between nucleotides demonstrating imino-imino NOEs, and nucleotide assignments for imino protons are labeled along the diagonal. Dashed lines connect imino-amino NOEs with the diagonal. Bottom panel depicts portions of a ${ }^{1} \mathrm{H}^{15} \mathrm{~N}$ HSQC spectrum that unambiguously distinguishes imino nitrogen resonances of U's (downfield, 156-162 ppm) from those of G's (upfield, 146-149 ppm). Top panel is a portion of a 350-msec mixing time NOESY spectrum acquired with the addition of $2 \mathrm{mM}$ cobalt(III) hexamine. Strong cross-peaks are observed between individual imino proton resonances and the averaged $\mathrm{Co}\left(\mathrm{NH}_{3}\right)_{6}{ }^{3+}$ hexammine resonance at $\sim 3.7 \mathrm{ppm}$. NMR data were processed with NMRPipe, and spectra were visualized using NMRDraw software (Delaglio et al. 1995).

construct. $\mathrm{Co}\left(\mathrm{NH}_{3}\right)_{6}{ }^{3+}$ has traditionally been employed as a fully coordinated magnesium hexahydrate mimic because it is strongly positively charged, and its octahedral geometry and the hydrogen-bonding capabilities of its exchange-inert ammonium ligands resemble those of the primary-shell water 
molecules of $\mathrm{Mg}\left(\mathrm{H}_{2} \mathrm{O}\right)_{6}{ }^{2+}$ (Kieft and Tinoco 1997; Gdaniec et al. 1998; Rudisser and Tinoco 2000). $\mathrm{Co}\left(\mathrm{NH}_{3}\right)_{6}{ }^{3+}$ amino protons give rise to an averaged ${ }^{1} \mathrm{H}-\mathrm{NMR}$ signal at $\sim 3.7 \mathrm{ppm}$, and NOEs to this distinctive resonance accurately identify metal ion binding sites within an RNA (Kieft and Tinoco 1997; Gdaniec et al. 1998; Rudisser and Tinoco 2000). Therefore, we collected NOESY spectra of exchangeable protons for the 885 construct upon addition of hexamminecobalt(III) chloride to a final concentration of $2 \mathrm{mM}$. Most of the imino proton resonances in the $\mathrm{H} 27$ construct exhibit weak cross-peaks to the hexammine resonance and thus association with the metal-ion complex, indicative of diffuse ion binding within the helix grooves. Only a select few resonances display stronger NOEs with the hexammine resonance, suggestive of more specific binding of $\mathrm{Co}\left(\mathrm{NH}_{3}\right)_{6}{ }^{3+}$ (Fig. 2, top panel). Significantly, relevant crystal structures of the $30 \mathrm{~S}$ ribosomal subunit depict a $\mathrm{Mg}^{2+}$ ion binding in the major groove of H27 near the G886-U911 pair (Brodersen et al. 2000; Carter et al. 2000; Ogle et al. 2001, 2002), consistent with the NOEs we observe from the G887 NH1 and U911 NH3 resonances to the averaged resonance of the ammonium ligands of the $\mathrm{Co}\left(\mathrm{NH}_{3}\right)_{6}{ }^{3+}$ complex (Fig. 2). Observation of such NOEs may be expected, since $\mathrm{Co}\left(\mathrm{NH}_{3}\right)_{6}{ }^{3+}$ was previously demonstrated to specifically bind to the unusual major groove geometry created by a tandem G-U wobble pair (Kieft and Tinoco 1997). In contrast, we do not observe a cross-peak between the ammonium ligands of $\mathrm{Co}\left(\mathrm{NH}_{3}\right)_{6}{ }^{3+}$ and the tetraloop G898 NH1 resonance.

Next, magnesium chloride titrations were performed to detect potential $\mathrm{Mg}^{2+}$ binding sites by chemical shift analysis for comparison with those from our $\mathrm{Co}\left(\mathrm{NH}_{3}\right)_{6}{ }^{3+}$ experiments and those found in relevant $30 \mathrm{~S}$ ribosomal subunit crystal structures (Brodersen et al. 2000; Carter et al. 2000; Ogle et al. 2001, 2002). Figure 3A shows onedimensional ${ }^{1} \mathrm{H}-\mathrm{NMR}$ spectra of the 885 construct acquired in the presence of increasing molar equivalents of $\mathrm{Mg}^{2+}$ (at an RNA concentration of $0.35 \mathrm{mM}$ in $10 \mathrm{mM}$ $\mathrm{Na}_{\mathrm{i}} \mathrm{PO}_{4}$ at $\mathrm{pH} 6.4,50 \mathrm{mM} \mathrm{NaCl}$ ). Almost every imino proton resonance in the molecule shifts slightly (typically $<0.05$ ppm) in position (Fig. 3B), indicating that $\mathrm{Mg}^{2+}$ binds diffusely throughout the molecule, and/or metal binding induces structural changes that result in a slight shifting of imino proton resonances. As is typical in NMR spectra of RNA, imino resonances broaden with the addition of high concentrations of $\mathrm{Mg}^{2+}$ ions; however, addition of low (millimolar) concentrations of $\mathrm{Mg}^{2+}$ first results in the narrowing of several resonances in the molecule, including those belonging to G886 NH1, G895 NH1, G898 NH1, G903 NH1, and U904 NH3, consistent with $\mathrm{Mg}^{2+}$-induced stabilization of local and/or global architecture within the molecule (Fig. 3A).

Specific resonances show relatively significant chemical shift changes with increasing metal ion concentration, suggesting possible specific association with $\mathrm{Mg}^{2+}$ (Fig. 3A,B), and/or more substantial rearrangements of local architecture
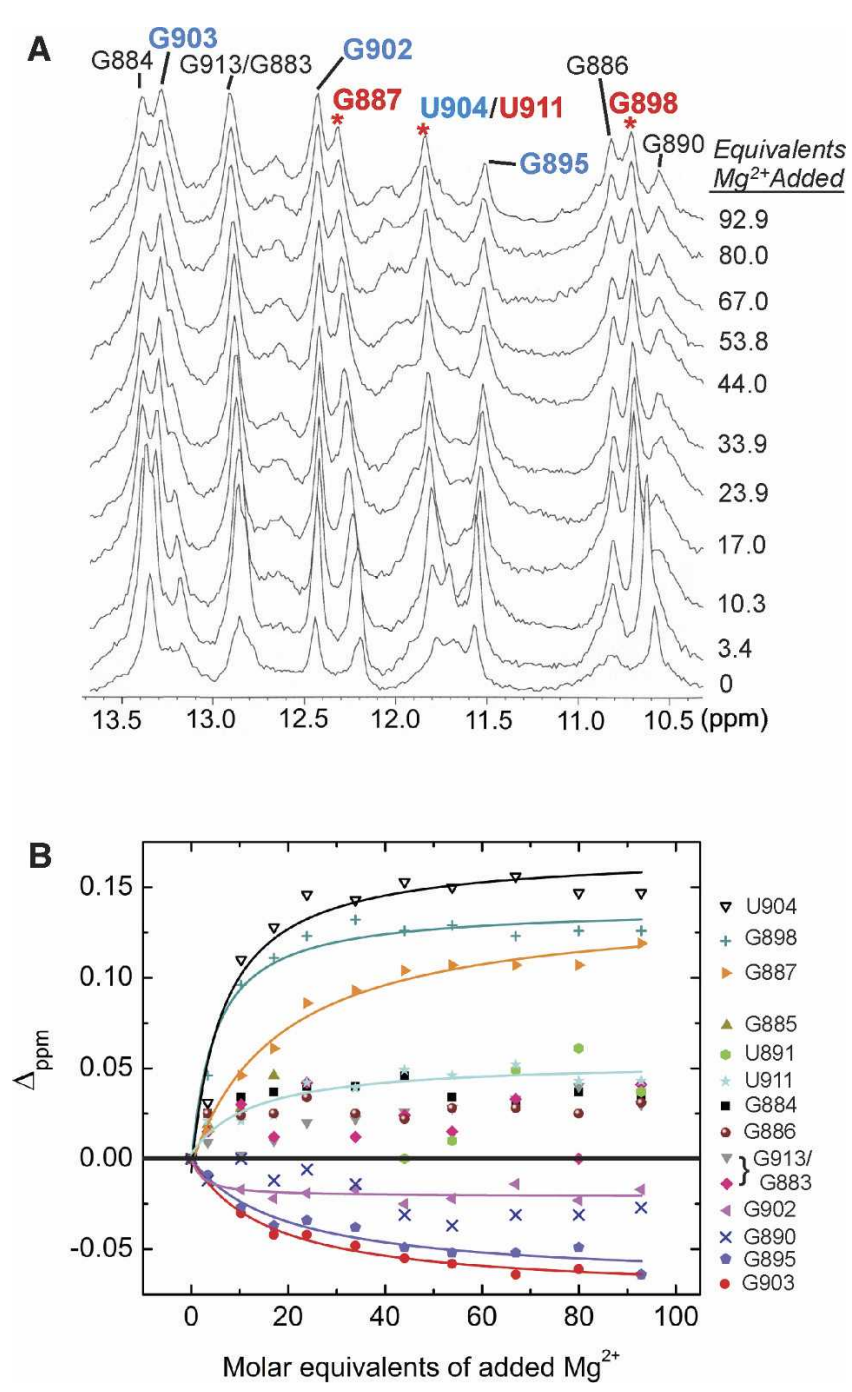

FIGURE 3. NMR-detected magnesium titrations of the H27 885 construct. (A) Stacked 885 imino proton spectra acquired with increasing $\mathrm{Mg}^{2+}$ concentration, as indicated by added molar equivalents. Imino proton resonance assignments are labeled, and those belonging to G887, G898, U911 are marked with asterisks in red, and those belonging to U904, G903, G902, and G895 are labeled in blue. (B) Plot of chemical shift changes for imino resonances of the 885 construct in dependence of the $\mathrm{Mg}^{2+}$ molar equivalents. Curves are shown for those resonances that fit to binding isotherms describing a one metal per site model (Lian and Roberts 1993; Gonzalez and Tinoco 1999). Individual resonance positions were found at each metal ion concentration by using the peak finder utility in nmrDraw, and by defining parameters for both a reasonable threshold for positive peak detection and a $\chi^{2}$ probability threshold for noise peak rejection, by $\chi^{2}$ test.

upon metal binding. For these resonances, chemical shift changes as a function of $\mathrm{Mg}^{2+}$ concentration were fit well with binding isotherms based on stoichiometric, fast exchange binding between the RNA site and a $\mathrm{Mg}^{2+}$ ion (Lian and Roberts 1993; Gonzalez and Tinoco 1999). The resulting relative $\mathrm{Mg}^{2+}$ half-titration points $\left(M g_{1 / 2}\right)$ are shown in Table 1. The tetraloop G898 NH1 resonance demonstrates a particularly large $(0.13 \mathrm{ppm})$ downfield 
shift with a corresponding $M g_{1 / 2}$ of $1.5 \pm 0.3 \mathrm{mM}$. This observation is consistent with previous studies that have shown that GNRA tetraloops bind $\mathrm{Mg}^{2+}$ tightly (Hermann and Westhof 1998; Maderia et al. 2000; Rudisser and Tinoco 2000; Mundoma and Greenbaum 2002). Other resonances that display significant downfield shifts were those of U904 $\mathrm{NH} 3(0.16 \mathrm{ppm})$ and G887 $\mathrm{NH} 1(0.12 \mathrm{ppm})$, with relative $\mathrm{Mg}^{2+}$ half-titration points of $\mathrm{Mg}_{1 / 2}=2.0 \pm 0.6 \mathrm{mM}$ and $M g_{1 / 2}=6.1 \pm 1.1 \mathrm{mM}$, respectively (Fig. 3B; Table 1). The resonance shift of U911 NH3 was less significant (0.05 ppm) but fit a binding isotherm, yielding $M g_{1 / 2}=5.4 \pm 1.2 \mathrm{mM}$ (Fig. 3B; Table 1). Other imino resonances display slight upfield shifts with increasing $\mathrm{Mg}^{2+}$ concentration that fit our stoichiometric binding model, namely, those belonging to G895 (-0.06 ppm), G902 (-0.02 ppm), and G903 $(-0.06 \mathrm{ppm})$; extracted relative $\mathrm{Mg}^{2+}$ half-titration points were $M g_{1 / 2}=6.5 \pm 2.3 \mathrm{mM}, M g_{1 / 2}=0.7 \pm 0.6 \mathrm{mM}$, and $M g_{1 / 2}=5.4 \pm 0.9 \mathrm{mM}$, respectively (Fig. 3B; Table 1). Among the latter six nucleotides, G902 participates in the closing base pair of the GCAA tetraloop, while G895, U904, and U911 participate in G-U wobble pairs, and G887 and G903 are adjacent to G-U wobble pairs. Such chemical shift changes are consistent with metal ion binding near these locations, as reported in other RNAs featuring G-U pairs (Kieft and Tinoco 1997; Gdaniec et al. 1998; Rudisser and Tinoco 2000) and GNRA tetraloops (Hermann and Westhof 1998; Maderia et al. 2000; Rudisser and Tinoco 2000; Mundoma and Greenbaum 2002). These data, however, cannot distinguish between the possibilities that the chemical shifts are due to either a direct impact of the cation or structural rearrangements affected by nearby metal ion binding. The fact that G887 and U911 imino proton resonances display

TABLE 1. Comparison of solution NMR spectroscopy and terbium footprinting data for potential metal ion binding sites within $\mathrm{H} 27$

\begin{tabular}{lcrcc}
\hline Nucleotide & $M g_{1 / 2}(\mathrm{mM})^{\mathrm{a}}$ & \multicolumn{1}{c}{$\begin{array}{c}\Delta_{\max } \\
(\mathrm{ppm})^{\mathrm{b}}\end{array}$} & $\begin{array}{c}\text { Strong NOE to } \\
\mathrm{Co}\left(\mathrm{NH}_{3}\right)^{3+} \\
\text { amino protons? }\end{array}$ & $\begin{array}{c}\text { Relative fraction } \\
\text { cleaved in } \\
\mathrm{Tb}^{3+} \text { footprinting } \\
\text { experiments } \\
(\text { normalized } \Pi)^{\mathrm{c}}\end{array}$ \\
\hline G887 & $6.1 \pm 1.1$ & $0.117 \pm 0.004$ & Yes & 0.19 \\
G895 & $6.5 \pm 2.3$ & $-0.057 \pm 0.004$ & No & 0.42 \\
G898 & $1.5 \pm 0.3$ & $0.132 \pm 0.004$ & No & 0.61 \\
G902 & $0.7 \pm 0.6$ & $-0.020 \pm 0.004$ & No & 0.38 \\
G903 & $5.4 \pm 0.9$ & $-0.064 \pm 0.004$ & No & 0.30 \\
U904 & $2.0 \pm 0.6$ & $0.157 \pm 0.004$ & No & 0.41 \\
U911 & $4.2 \pm 2.4$ & $0.048 \pm 0.004$ & Yes & 0.16 \\
\hline
\end{tabular}

${ }^{\mathrm{a}} \mathrm{Mg}_{1 / 2}$ values were determined from the one metal per site model described in Materials and Methods, where the total $\mathrm{Mg}^{2+}$ ion concentration is used as input (Lian and Roberts 1993; Gonzalez and Tinoco 1999). This concentration does not necessarily reflect the (unknown) free metal ion concentration so that the derived relative half-titration points $M g_{1 / 2}$ should only be compared among the resonance shifts observed here (Tanaka and Taira 2005).

${ }^{\mathrm{b}}$ Reported $\Delta_{\max }$ values are accurate within the digital resolution of the spectrum, which is 0.004 ppm.

${ }^{\mathrm{c}}$ As defined in Materials and Methods (Harris et al. 2004) and normalized to $\Pi_{\mathrm{C} 899}$. strong NOESY cross-peaks to the ammonium ligands of $\mathrm{Co}\left(\mathrm{NH}_{3}\right)_{6}{ }^{3+}$ (Fig. 2) does provide such a distinction and supports the existence of a metal ion binding site in this region, next to the G886-U911 wobble pair. By contrast, we found no evidence for a strong NOE between the tetraloop G898 NH1 resonance and the $\mathrm{Co}\left(\mathrm{NH}_{3}\right)_{6}{ }^{3+}$ amino proton, or was there evidence for such an NOE involving the U904 33 resonance, although these two resonances display the significant shifts upon addition of $\mathrm{Mg}^{2+}$; a possibility is sites within $\mathrm{H} 27$.

\section{Terbium(III)-mediated footprinting confirms secondary}

The lanthanide metal ion terbium(III) has been used to footprint the secondary and tertiary structure of various RNAs and to identify potential regions of enhanced structural dynamics and $\mathrm{Mg}^{2+}$ binding (Ciesiolka et al. 1989; Hargittai and Musier-Forsyth 2000; Walter et al. 2000; Jeong et al. 2003; Harris et al. 2004). $\mathrm{Tb}^{3+}$ facilitates RNA backbone scission by first binding near the negatively charged backbone phosphate groups and then abstracting the proton from a nearby $2^{\prime}$ hydroxyl group. The resulting $2^{\prime}$ oxyanion attacks the adjacent phosphodiester linkage, which results in scission of the nucleotide chain at that ocation (Ciesiolka et al. 1989; Matsumura and Komiyama 2pecific metal binding sites, single-stranded tracts, vulnerable to $\mathrm{Tb}^{3+}$-induced hydrolysis (Harris and Walter 2003; Sigel and Pyle 2003; Harris and Walter 2005). However, slow scission at all nucleotides will eventually occur at sufficiently high terbium(III) concentrations.

Here we have utilized $\mathrm{Tb}^{3+}$-mediated footprinting as a complementary biochemical technique to map the secondary structure and $\mathrm{Mg}^{2+}$ binding sites in the 885 conformation of H27. Trace amounts (to a final concentration of $<4 \mathrm{nM})$ of ${ }^{32} \mathrm{P}$ radiolabeled footprinting construct Tb885 (with a further extended terminal helix) were incubated with $2 \mathrm{mM}$ $\mathrm{Tb}^{3+}$ in $50 \mathrm{mM}$ Tris (pH 7.5), $20 \mathrm{mM}$ $\mathrm{MgCl}_{2}$, and $50 \mathrm{mM} \mathrm{NH}_{4} \mathrm{Cl}$ at $25^{\circ} \mathrm{C}$ for 2 $\mathrm{h}$ and subsequently analyzed on a denaturing polyacrylamide sequencing gel. Normalized fractions of terbium(III)mediated scission (expressed as ratio $\Pi$, see Materials and Methods), obtained from the quantified gel bands, are shown in Figure 4A. A schematic of the Tb885 secondary structure with quantified $\mathrm{Tb}^{3+}$ hits (occurring between the indicated nucleotides) is shown in 


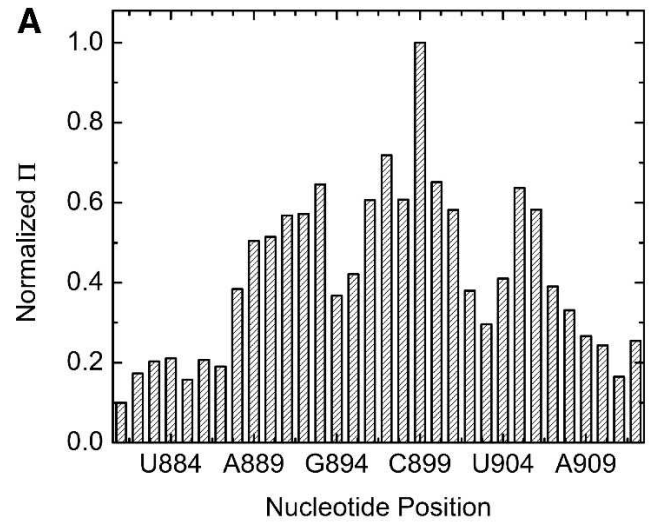

B

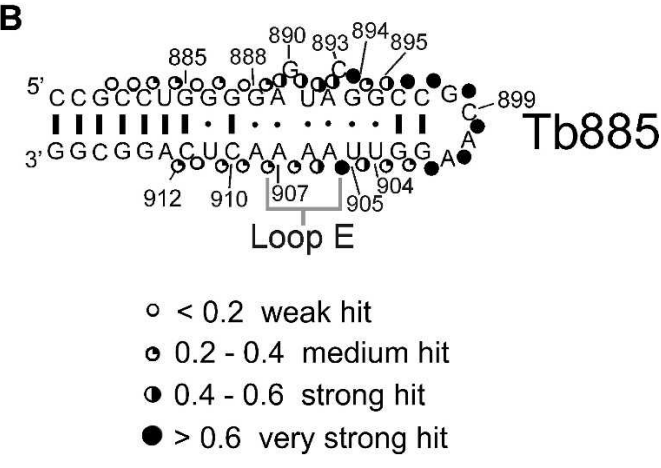

FIGURE 4. Terbium footprinting of the helix 27 Tb885 construct. (A) Bar graph representing relative extents of scission $3^{\prime}$ of each nucleotide, $\Pi$, as defined in Materials and Methods. Data were normalized relative to $\Pi_{\mathrm{C} 899}$. (B) Secondary structure for the Tb885 construct used for terbium(III) footprinting studies. The relative strength of the $\mathrm{Tb}^{3+}$ hit $3^{\prime}$ of each nucleotide is shown mapped onto the secondary structure.

Figure 4B. It reveals that, in general, nucleotides G888-A907 of Tb885 are cut with significantly (up to twofold) greater probability than were regions G881-G887 and A908-C912. These more labile backbone regions are components of the loop E motif, adjacent G-U tandem wobble pairs, and GNRA tetraloop (Fig. 4). The loop E motif is characterized by an unusual, S-shaped backbone conformation (Leontis and Westhof 1998). We find that this backbone geometry and perhaps its dynamics make the phosphodiester bonds in this region comparatively vulnerable to scission (Fig. 4), similar to observations for the related loop $\mathrm{E}$ motif of the hairpin ribozyme (Walter et al. 2000). Other strong $\mathrm{Tb}^{3+}$ hits within Tb885 are clustered toward the side of the loop E motif closed by the (weak) G894-U905 pair, consistent with metal ion binding in the vicinity of the G894-U905/G895-U904 tandem wobble pairs, in accord with our NMR data. Particularly intense $\mathrm{Tb}^{3+}$ hits are observed in the tetraloop region, a documented lanthanide metal binding site (Mundoma and Greenbaum 2002), in good agreement with our NMR data that suggest metal ion binding in the loop. Table 1 compares our terbium(III)-mediated footprinting data for nucleotides where NMR provides independent evidence of nearby metal ion binding.
In summary, our $\mathrm{Tb}^{3+}$ data support several conclusions from our NMR studies. In particular, scission patterns of the Tb885 construct are consistent with the proposed secondary structure, with weak cuts in the predicted helical regions and stronger cuts in the noncanonical loop E motif, tandem G894-U905 wobble pair, and tetraloop. These observations support the notion that $\mathrm{Mg}^{2+}$ binding sites reside within the non-Watson-Crick base-paired regions of $\mathrm{H} 27$.

\section{tr-FRET reveals differences in end-to-end distance of 885 upon $\mathrm{Mg}^{2+}$ binding}

We find NMR to be a reliable reporter of local structure and metal binding in the $\mathrm{H} 27$ conformers, but the observed short-range $(<5 \AA)$ NOE interactions are poor indicators of global conformation. To aid in assessment of more generalized $\mathrm{Mg}^{2+}$-induced changes in $\mathrm{H} 27$ architecture, tr-FRET was employed. tr-FRET is an established tool to determine, at Ångstrom resolution, long-range distances between donor and acceptor fluorophores attached to specific sites in an RNA (Rueda et al. 2003; Tinsley et al. 2004). A conformationally locked 885 construct was synthesized and labeled with donor fluorescein attached to nucleotide 899 in the tetraloop and acceptor tetramethylrhodamine conjugated to a linker on nucleotide 911 in the terminal helix, generating tr-FRET construct F885T. In the absence of $\mathrm{Mg}^{2+}$ (in $50 \mathrm{mM}$ Tris- $\mathrm{HCl}$, $\mathrm{pH}$ 7.5, $50 \mathrm{mM} \mathrm{NH}{ }_{4} \mathrm{Cl}$; we also repeated these experiments, with similar results, in $10 \mathrm{mM} \mathrm{NaP}_{\mathrm{i}}$ at $\mathrm{pH} 7.0,50$ $\mathrm{mM} \mathrm{NaCl}, 0.1 \mathrm{mM}$ EDTA, close to our NMR buffer except for a higher $\mathrm{pH}$ to enhance the fluorescein fluorescence; see Materials and Methods), the mean of the tr-FRETderived donor-acceptor fluorophore distance distribution is $51.6 \pm 0.2 \AA$. Upon $\mathrm{Mg}^{2+}$ addition, this mean distance increases to a maximum of $53.1 \pm 0.2 \AA$ with a $\mathrm{Mg}^{2+}$ halftitration point of $\mathrm{Mg}_{1 / 2}=0.44 \pm 0.06 \mathrm{mM}$, as extracted from a modified Hill fit of the distance profile (see Materials and Methods; Fig. 5). The full width at half maximum (fwhm) of the distance distribution also slightly increases (by $<10 \%$ ) (data not shown). The overall lengthening observed for F885T at high $\mathrm{Mg}^{2+}$ concentrations is consistent with our NMR data, which suggest that the 885 conformation is stabilized by the uptake of $\mathrm{Mg}^{2+}$.

\section{DISCUSSION}

We here have characterized, by several solution probing techniques, $\mathrm{Mg}^{2+}-\mathrm{RNA}$ interactions within a conformationally locked construct representing the 885 conformation of H27 from E. coli 16S rRNA. Our model construct appears to diffusely bind magnesium hexahydrate throughout its full length, as evidenced by the slight shifting of nearly every imino proton resonance upon $\mathrm{Mg}^{2+}$ addition, 


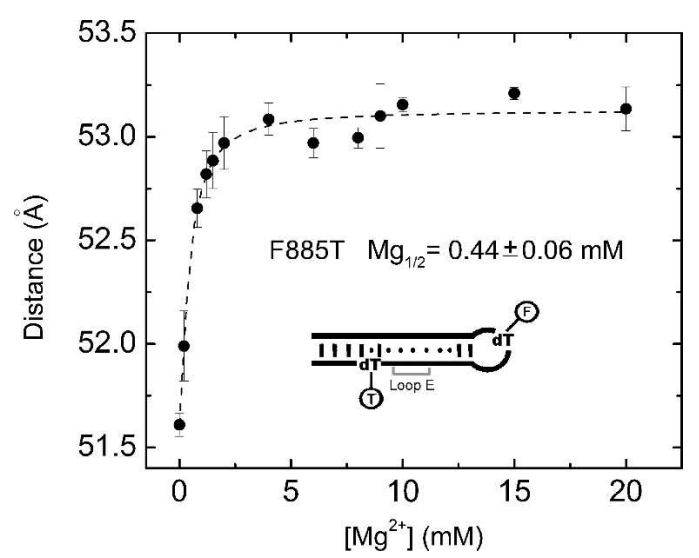

FIGURE 5. Time-resolved FRET monitored magnesium titrations of the helix 27 F885T construct demonstrates global structural changes upon $\mathrm{Mg}^{2+}$ binding. The mean distances between donor and acceptor fluorophore are shown as a function of $\mathrm{Mg}^{2+}$ concentration, and the curve has been fit to a modified Hill equation, yielding the apparent $\mathrm{Mg}^{2+}$ half-titration value, $M g_{1 / 2}$, as indicated (Hill coefficient $(\mathrm{n})=1.3$, which is close to unity, indicating a lack of metal binding cooperativity). Fluorophores are attached to the F885T construct at the dT nucleotides, positions 899 and 911, as indicated.

and undergoes small-scale global conformational rearrangements and/or stabilization upon $\mathrm{Mg}^{2+}$ titration, as suggested by an increase in tr-FRET detected end-to-end distance. NMR NOESY spectra provide evidence for sitespecific association of $\mathrm{Co}\left(\mathrm{NH}_{3}\right)_{6}{ }^{3+}$ with the widened major groove of the G886-U911 pair, as is seen for other RNAs containing G-U wobbles (Kieft and Tinoco 1997; Gdaniec et al. 1998; Rudisser and Tinoco 2000). NMR chemical shift analyses support $\mathrm{Mg}^{2+}$ binding adjacent to tandem G894U905/G895-U904 wobble pairs, while $\mathrm{Tb}^{3+}$ footprinting indicates enhanced susceptibility to metal-induced cleavage in this region. NMR chemical shift data and $\mathrm{Tb}^{3+}$ footprinting also support the notion of a $\mathrm{Mg}^{2+}$ binding site within the GCAA tetraloop of the molecule. Neither of the latter two sites detectably accommodates $\mathrm{Co}\left(\mathrm{NH}_{3}\right)_{6}{ }^{3+}$.

\section{Helix 27 in the context of the ribosome}

In phylogenetic comparisons of $16 \mathrm{~S}$ rRNAs, H27 shows very little variation among species (Gutell et al. 1985). In all ribosomal crystal structures to date, the loop E motif of the 885 conformation is observed (Carter et al. 2000; Wimberly et al. 2000); the H27 GCAA tetraloop forms tertiary hydrogen bonds with a tetraloop receptor in helix 24 of $16 \mathrm{~S}$ rRNA (Belanger et al. 2004) and is involved in an intersubunit bridge; the bulged C893 is involved in a cis-Watson-Crick pair with U244; and A909 forms a cis sugar edge/ sugar edge interaction with A1413 (Carter et al. 2000; Wimberly et al. 2000). The alternate 888 conformation, first proposed in 1995 based on comparative analysis of 16S rRNA sequences (Lodmell et al. 1995), was later demonstrated not to be a requisite for protein synthesis in E. coli (Rodriguez-Correa and Dahlberg 2004). However, an isolated $\mathrm{H} 27$ adopts a dynamic equilibrium between the 885 and 888 conformations (Hoerter et al. 2004). It is therefore possible that the structural and electrostatic environment surrounding $\mathrm{H} 27$ within the ribosome may slightly alter its structural and metal binding properties from those observed in our solution studies.

Our NMR and terbium footprinting data indicate that the loop E motif of the 885 conformation of $\mathrm{H} 27$ is an example of an RNA segment that exhibits small-scale motions. Terbium footprinting reveals that a large portion of the RNA has a relatively susceptible backbone that is prone to $\mathrm{Tb}^{3+}$-induced scission, indicative of sufficient flexibility to accommodate attack of the deprotonated $2^{\prime}$ hydroxyl on the adjacent phosphodiester bond. In addition, low concentrations of $\mathrm{Mg}^{2+}$ result in the sharpening of several imino proton resonances, consistent with structural stabilization upon addition of metal. Finally, tr-FRET analyses demonstrate a lengthening of our $\mathrm{H} 27$ construct with increasing $\mathrm{Mg}^{2+}$, consistent with metal ion-induced stabilization of the helix.

\section{Some, but not all, $\mathrm{Mg}^{2+}$ interactions in the $\mathbf{8 8 5}$ conformation are depicted in the relevant $30 \mathrm{~S}$ ribosomal subunit crystal structures}

Crystal structures of the $30 \mathrm{~S}$ ribosomal subunit that describe coordinates for site-bound $\mathrm{Mg}^{2+}$ ions do not depict any direct contacts between helix 27 and the small ribosomal subunit proteins (Brodersen et al. 2000; Carter et al. 2000; Ogle et al. 2001, 2002), making it one of the few small subunit helices that do not directly interact with protein. Its only near-contact is with the relatively unstructured cationic N-terminal tail of S12 that extends into a pocket adjacent to H27, where lysine 21 lies within $3.7 \AA$ of each one nonbridging phosphate oxygen of A908 and A909 (Carter et al. 2000). The associated long-range electrostatic interaction may stabilize the 885 over the 888 conformation in the context of the ribosome, while they are close to isoenergetic in isolation (Hoerter et al. 2004). Recent studies on the 50S subunit have revealed that metal ions are particularly concentrated in conserved regions of an RNA where proteins are absent (Klein et al. 2004), suggesting that H27 may represent a strong metal ion binding region. In addition, thermal denaturation studies of loop E motifs revealed a particularly strong $\mathrm{Mg}^{2+}$ ion dependence for the melting profiles of these RNA constructs, implying that loop E motifs bind $\mathrm{Mg}^{2+}$ ions specifically (Serra et al. 2002). Relevant crystal structures of the $30 \mathrm{~S}$ ribosomal subunit indeed depict two $\mathrm{Mg}^{2+}$ ions bound to $\mathrm{H} 27$ (Brodersen et al. 2000; Carter et al. 2000; Ogle et al. 2001, 2002): one (Mg73) in the major groove adjacent to the G886-U911 wobble pair, and one (Mg126) nestled in the GCAA tetraloop (Fig. 6A-C). 

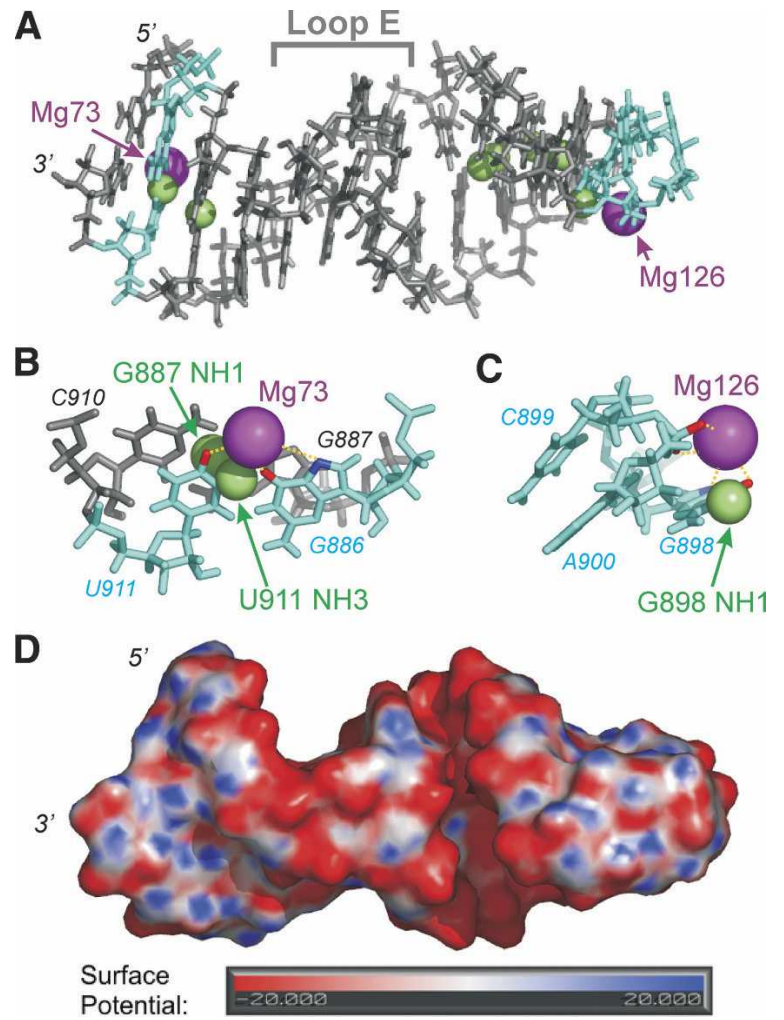

FIGURE 6. Map of protons in the 885 conformation of helix 27 that demonstrate either NOEs with cobalt(III) hexammine and/or significant spectral shifts upon addition of $\mathrm{Mg}^{2+}$ that fit to a one metal per site model, shown in relation to $\mathrm{Mg}^{2+}$ binding sites in the $30 \mathrm{~S}$ ribosomal subunit crystal structure. (A) Crystal structure of helix 27 (nucleotides G885-C912) from 16S rRNA in the 30S ribosomal subunit of Thermus thermophilus (PDB identification no. 1FJG) (Carter et al. 2000). There are two site-bound $\mathrm{Mg}^{2+}$ ions assigned in the crystal structure, $\mathrm{Mg} 73$ and Mg126, shown in magenta. Nucleotides that are shown to bind the metal ions in crystal structures are colored aqua, and protons that NMR data suggest may be interacting with metal ions (U911 NH3, G887 NH1, U904 NH3, G895 NH1, G903 NH1, G902 NH1, and G898 NH1) are depicted as green spheres. (One of the T. thermophilus C904 amino protons is highlighted to represent the location of the homologous E. coli U904 NH3) proton.) (B) Close-up view of the Mg73 binding pocket. This metal ion is situated within the major groove of H27, interacting with the G886-U911 wobble pair. Nearby RNA keto oxygen and ring nitrogen ligands are colored red and blue: G886 O6 at a $2.82 \AA$ distance; G886 N7, $4.09 \AA$; and U911 O4, $3.14 \AA$. U911 NH3 and G887 NH1, demonstrating strong NOEs with cobalt(III) hexammine in NOESY spectra of 885 , are represented again as green spheres. $(C)$ Enlarged view of the tetraloop binding pocket occupied by Mg126. This metal ion is observed at a distance of $3.28 \AA$ and $3.77 \AA$ from O6 and N7 (red and blue, respectively) of the Hoogsteen face of A898 and at a distance of $5.11 \AA$ and $5.38 \AA$ from the nonbridging phosphate oxygens (red) of A900. In our experiments, the G898 NH1 proton (green sphere) shows a dramatic chemical shift in NMR spectra upon addition of $\mathrm{Mg}^{2+}$. (D) Electrostatic surface potential map of H27 from the $30 \mathrm{~S}$ subunit crystal structure, shown in the same orientation as panel $A$. The S-turn in the backbone creates an unusually deep and narrow major groove that is dense with negative charge, and is likely to be a strong cation binding sink. The U904 NH3 and G895 NH1 protons within this groove (indicated in $A$ by green spheres), shift considerably in resonance upon addition of $\mathrm{Mg}^{2+}$. This figure was generated by using pyMOL software (DeLano 2002).
How do solution probing data compare with these crystallographically resolved $\mathrm{Mg}^{2+}$ ions? Crystallographic conditions have typically employed 10-15 $\mathrm{mM} \mathrm{Mg}^{2+}$, introduced as magnesium acetate and/or magnesium chloride salts (Clemons et al. 2001). These concentrations are comparable to the concentrations of free $\mathrm{Mg}^{2+}$ used in our solutions studies $(0-20 \mathrm{mM} \mathrm{MgCl}$ ). Table 1 and Figure 6 summarize nucleotides where we observe strong NOEs upon the addition of cobalt(III) hexammine as a fully hydrated (outersphere coordinated) $\mathrm{Mg}^{2+}$ mimic and/or significant chemical shifts in NMR spectra upon addition of $\mathrm{Mg}^{2+}$. We find three different scenarios when comparing solution with crystallographic data. First, the imino protons G887 NH1 and U911 NH3 show cobalt(III) hexammine NOEs as well as $\mathrm{Mg}^{2+}$-induced downfield chemical shifts (of $0.12 \mathrm{ppm}$ and $0.05 \mathrm{ppm}$, respectively) in solution (Table 1). Both protons are proximal to Mg73 of the ribosomal crystal structures (Fig. 6A,B), which has its closest contacts with G886 O6, G886 N7, and $\mathrm{U} 911 \mathrm{O} 4$ at $2.82 \AA, 4.09 \AA$, and $3.14 \AA$, respectively (Fig. 6B). A subset of $30 \mathrm{~S}$ subunit crystal structures, such as Protein Data Bank (PDB) 1IBM (Ogle et al. 2001), assigns an additional $\mathrm{Mg}^{2+}$ ion, $\mathrm{Mg} 406$, coordinated to G887 N7 at a distance of $3.26 \AA$. Both the NMR and crystallographic data are therefore consistent with outersphere coordination of $\mathrm{a} \mathrm{Mg}^{2+}$ ion in the major grove of this region, next to the G886-U911 wobble pair.

Second, G898 NH1 in the GCAA tetraloop does not detectably coordinate with cobalt(III) hexammine in solution but shows one of the most pronounced downfield chemical shifts $(0.13 \mathrm{ppm})$ upon titration with $\mathrm{Mg}^{2+}$. In the crystal structures, Mg126 is coordinated to G898 O6 and G898 N7 at distances of $3.28 \AA$ and $3.77 \AA$, respectively (Fig. 6C). Again, the NMR chemical shift and crystallography data are both consistent with outersphere coordination of $\mathrm{Mg}^{2+}$ ion in the major groove of the GNRA tetraloop, in agreement with previous observations in other RNAs (Hermann and Westhof 1998; Maderia et al. 2000; Rudisser and Tinoco 2000; Mundoma and Greenbaum 2002). The fact that no NOE to the cobalt(III) hexammine ligands is observed suggests that the high-charge-density, exchangeinert cobalt(III) complex may bind at a (slightly) different location or with lower affinity than $\mathrm{Mg}^{2+}$.

In the third case, strong evidence for metal ion binding within the major groove of the helix between the loop $\mathrm{E}$ motif and the GCAA tetraloop was observed in our solution studies, while such a metal ion binding site was not detected in ribosomal 30S subunit crystal structures that describe magnesium ion binding (Brodersen et al. 2000; Carter et al. 2000; Ogle et al. 2001, 2002). More specifically, $\mathrm{Tb}^{3+}$ footprinting studies revealed that nucleotides G888-A907 of Tb885 are cut with significantly (up to twofold) greater probability than are regions G881-G887 and A908-C912, consistent with metal ion association with the GCAA tetraloop, as well as the loop 
E motif and tandem G-U pairs (Fig. 4A,B). NMR data are also suggestive of metal ion binding in the vicinity of the tandem GU pairs, as the G895 NH1, G902 NH1, G903 NH1, and U904 NH3 imino proton resonances all display significant titratable shifts upon addition of $\mathrm{Mg}^{2+}$ (Fig. 3; Table 1). In particular, the U904 NH3 resonance shifts downfield more than does any other resonance in the molecule $(0.16 \mathrm{ppm})$, while the other three resonances shift upfield. While there are no metal ions resolved crystallographically around G895 NH1, G902 $\mathrm{NH} 1, \mathrm{G} 903 \mathrm{NH1}$, and U904 NH3, these protons are positioned deeply within the highly negatively charged major (deep) groove adjacent to the loop E motif, which is expected to be a particularly strong metal ion binding site (Fig. 6A,D; Correll et al. 1997; Serra et al. 2002; Auffinger et al. 2004; Reblova et al. 2004). We therefore propose that $\mathrm{Mg}^{2+}$ either binds near the tandem G894-U905/G895U904 wobble pairs in solution and not in the crystal or, alternatively, that binding is transient under both sets of conditions (possibly explaining why no NOE with $\mathrm{Co}\left(\mathrm{NH}_{3}\right)_{6}{ }^{3+}$ hexammine protons was observed) so that the metal ion occupancy at this site is too low to produce an assignable signal in crystallographic electron density maps. In addition, if we consider the slightly higher monovalent cation concentration used in crystallization $(50-200$ $\mathrm{mM})$ than utilized in our solution studies $(50-100 \mathrm{mM})$, we cannot rule out the possibility that this particular site is occupied by (undetected) monovalents in the $30 \mathrm{~S}$ crystal structures.

In summary, we have gathered experimental evidence for metal ion interactions within the distorted major groove near tandem G-U wobble pairs of an isolated helix 27 from E. coli 16S rRNA, which are not depicted in any $30 \mathrm{~S}$ ribosomal subunit crystal structures. In addition, we find that even in a conformationally stabilized 885 structure, small-scale dynamics occur, and that millimolar $\mathrm{Mg}^{2+}$ concentrations attenuate these motions. We propose that the interplay of local $\mathrm{H} 27$ base and backbone dynamics, as detected here by NMR and terbium footprinting studies, respectively, may contribute to differences in detectable metal ion interactions between dynamic solution structures and relatively static crystal structures. Our studies thus highlight the necessity to continue to complement crystallographic with solution phase detection of metal ion binding in RNA.

\section{MATERIALS AND METHODS}

\section{Design and synthesis of the helix 27 NMR construct}

Helix 27 RNA construct 885 (5'-GGCGGGGAGUACGGCCGC AAGGUUAAAACUCGCC-3') (Fig. 1B) was designed with the addition of extra $\mathrm{G}$ and $\mathrm{C}$ nucleotides to the helix terminus of the natural $\mathrm{H} 27$ sequence to stabilize the 912-885 conformation over the 912-888 and prevent switching between the two $\mathrm{H} 27$ base-pairing patterns. The molecule was transcribed in vitro from a double-stranded DNA template containing a T7 RNA polymerase promoter region, as described previously (Hoerter et al. 2004). For the uniformly ${ }^{13} \mathrm{C} /{ }^{15} \mathrm{~N}$-labeled sample, isotopically enriched nucleotides (Silantes) were substituted for unlabeled nucleotide triphosphates. Following transcription, EDTA was added to the reactions to a final concentration of $60 \mathrm{mM}$, and reaction mixtures were extracted with an equal volume of phenol followed by two extractions with equal volumes of a $24: 1 \mathrm{CHCl}_{3}$ :isoamyl alcohol mixture. Centricon-3 centrifugal filter devices (Amicon) were used to concentrate the protein-free extracts and remove excess nucleoside triphosphates. H27 885 samples were then separated from abortive transcripts and template DNA by electrophoresis on denaturing, $8-\mathrm{M}$ urea, $20 \%$ polyacrylamide gels. RNA was detected by UV shadowing, and appropriate bands were excised and eluted by crushing and soaking in $5 \mathrm{mM}$ EDTA. The RNAs were further purified by anion exchange with Sephadex A-25 resin and exchanged into NMR buffer (10 $\mathrm{mM} \mathrm{Na}_{\mathrm{i}} \mathrm{PO}_{4}$ at $\mathrm{pH}$ 6.4, $0.1 \mathrm{mM}$ EDTA, $50 \mathrm{mM} \mathrm{NaCl}$ ) by using Centricon-3 concentrators. Samples were concentrated to $\sim 200 \mu \mathrm{L}$, and $99.9 \% \mathrm{D}_{2} \mathrm{O}$ (Aldrich) and NMR buffer were each added to the samples in predetermined amounts so that the final volume for each sample was $225 \mu \mathrm{L}$, and the final concentration of $\mathrm{D}_{2} \mathrm{O}$ (for lock) was $5 \%$. Final concentrations, determined by absorbances at $260 \mathrm{~nm}$, were $\sim 0.35 \mathrm{mM}$ and $\sim 0.6 \mathrm{mM}$ for the homonuclear and ${ }^{13} \mathrm{C} /{ }^{15} \mathrm{~N}$ isotopically labeled samples, respectively. $\mathrm{D}_{2} \mathrm{O}$-matched microvolume NMR tubes (Shigemi) were used for data collection.

\section{NMR data acquisition and processing}

One-dimensional $\mathrm{Mg}^{2+}$ titration experiments with the 885 construct were performed at $4^{\circ} \mathrm{C}$ on a $600-\mathrm{MHz}$ Bruker Avance spectrometer. Spectra were collected with 128 transients, and a jump-and-return water suppression scheme coupled with a WATERGATE pulse train was utilized (Piotto et al. 1992; Grzesiek and Bax 1993). Sterile-filtered $1 \mathrm{M}$ and $100 \mathrm{mM}$ stock solutions of magnesium chloride hexahydrate, 99.995\% (Aldrich), were carefully added to each sample to stepwise increase their $\mathrm{Mg}^{2+}$ concentrations. Magnesium ion concentrations noted in Figure 3 and referred to throughout the text reflect the final concentration of the added metal ions in molar equivalents, relative to the RNA concentration, and are not adjusted to reflect the free metal ion concentrations according to uptake of metal ions by the RNA or the $0.1 \mathrm{mM}$ EDTA background present in the NMR sample buffer. The sample was allowed to re-equilibrate at $5^{\circ} \mathrm{C}$ and was relocked and reshimmed, the probe was retuned, and the $\Pi / 2$ pulse was recalibrated for each $\mathrm{Mg}^{2+}$ concentration. Spectra were processed with NMRPipe by using a solvent filter and a cosinebell apodization function and were zero-filled once before Fourier transforming (Delaglio et al. 1995). NMRDraw was used to visualize each spectrum and detect peaks (Delaglio et al. 1995). Data were then reprocessed by using Bruker software to create the stacked plot shown in Figure 3. Plots of chemical shift (accurate to an error of about $\pm 0.004 \mathrm{ppm}$ due to limited digital resolution of the spectrum; i.e., sweep width [ppm] divided by number of acquisition points) versus added $\mathrm{Mg}^{2+}$ equivalents were fit with the following binding isotherm 
for a system in fast exchange, where the RNA concentration is of the same magnitude as the metal ion concentration (Lian and Roberts 1993; Gonzalez and Tinoco 1999).

$$
\begin{gathered}
\delta_{o b s}=\delta_{f}+\left(\delta_{b}-\delta_{f}\right)\left\{\frac{\left[[i o n]_{t}+[R N A]_{t}+M g_{1 / 2}\right]}{2[R N A]_{t}}\right\} \\
-\left(\delta_{b}-\delta_{f}\right)\left\{\frac{\sqrt{\left([i o n]_{t}+[R N A]_{t}+M g_{1 / 2}\right)^{2}-\left(4[R N A]_{t}[i o n]_{t}\right)}}{2[R N A]_{t}}\right\}
\end{gathered}
$$

$\delta_{o b s}$ is the observed chemical shift, $\delta_{f}$ is the chemical shift of the unbound imino proton, $\delta_{b}$ is the chemical shift of the fully bound proton, [ion $]_{t}$ is the total added magnesium ion concentration in $\mathrm{mM},[R N A]_{t}$ is the RNA concentration, and $M g_{1 / 2}$ is the magnesium half-titration point. Chemical shifts reported are accurate within the digital resolution of the spectrum, or sweep width (ppm) divided by the number of acquisition points. The digital resolution in the $\mathrm{Mg}^{2+}$ titration data is therefore $0.004 \mathrm{ppm}$. It should be noted that the $\mathrm{Mg}^{2+}$ concentrations used to compute the binding isotherms are added metal ion concentrations and do not reflect the true free metal ion concentration since the polyanionic RNA uptakes an unknown number of the metal ions in solution. Therefore, the extracted magnesium half-titration points, $M g_{1 / 2}$, can only be compared relative to those of other resonance shifts within the same sample (Tanaka and Taira 2005).

NOESY spectra of exchangeable protons with and without cobalt(III) hexammine, as well as the imino ${ }^{1} \mathrm{H}_{-}{ }^{15} \mathrm{~N}$ HSQC spectrum, were also acquired at $5^{\circ} \mathrm{C}$ on the Bruker Avance $600-\mathrm{MHz}$ spectrometer. NOESY spectra were collected with 350- and 150msec mixing times for samples with and without $2 \mathrm{mM}$ hexamminecobalt(III) chloride, $99.999 \%$ (Aldrich), respectively. NOESYs were acquired with 2048 complex points, 256 increments, and a sweep width of $12,019.231 \mathrm{~Hz}$ in both the directly and indirectly detected dimensions. The carrier was placed at the water proton resonance position in all cases. In the ${ }^{1} \mathrm{H}_{-}{ }^{15} \mathrm{~N}$ HSQC experiment, ${ }^{15} \mathrm{~N}$ decoupling parameters, delays, sweep width $(1824.568 \mathrm{~Hz})$, and carrier position $(150.911 \mathrm{~Hz})$ were optimized for observation of imino ${ }^{1} \mathrm{H}^{-15} \mathrm{~N}$ cross-peaks; 2048 complex points and 512 increments were collected, with a ${ }^{1} \mathrm{H}$ sweep width of $17985.612 \mathrm{~Hz}$. In these experiments, quadrature detection was achieved by implementation of the States-TPPI method (Marion et al. 1989), and spectra were processed and visualized with NMRPipe and NMRView software (Delaglio et al. 1995). Processing for these spectra included apodization with a cosine-bell function, application of a solvent filter, and zerofilling once prior to Fourier transforming.

\section{Terbium(III) footprinting experiments}

Helix 27 construct Tb885 (5'-CCGCCUGGGGAGUACGGCCGC AAGGUUAAAACUCAGGCGG-3') was obtained commercially (Dharmacon) and deprotected according to manufacturer's protocols. Tb885 was subsequently $5^{\prime}$ end labeled by using $\left[\gamma^{32} \mathrm{P}\right] \mathrm{ATP}$ and purified by denaturing, 8 -M urea, $20 \%$ polyacrylamide gel electrophoresis. The band corresponding to the H27 construct was excised and eluted by diffusion into $1 \mathrm{mM}$ EDTA overnight at $4^{\circ} \mathrm{C}$ and then was ethanol precipitated. For the footprinting reactions, radiolabeled $\mathrm{Tb} 885$ (to a final concentration of $<4 \mathrm{nM}$ ) was first dissolved in $5 \mu \mathrm{L} 2 \times$ annealing buffer (100 mM Tris at $\mathrm{pH} 7.5,40 \mathrm{mM} \mathrm{MgCl}_{2}, 100 \mathrm{mM} \mathrm{NH}_{4} \mathrm{Cl}$ ) and 4 $\mu \mathrm{L}$ distilled deionized water, heated for $2 \mathrm{~min}$ at $70^{\circ} \mathrm{C}$, and allowed to cool for $5 \mathrm{~min}$ at room temperature. One microliter of $10 \times \mathrm{Tb}^{3+}$ solution $\left(20 \mathrm{mM} \mathrm{TbCl}_{3}, 5 \mathrm{mM} \mathrm{MES}\right.$ at $\left.\mathrm{pH} 5.5\right)$ was added to the reaction mixture and incubated for $2 \mathrm{~h}$ at $25^{\circ} \mathrm{C}$. A control reaction containing $5 \mathrm{mM}$ MES ( $\mathrm{pH}$ 5.5) buffer, instead of $10 \times \mathrm{Tb}^{3+}$ buffer, was also run in parallel; $50 \mathrm{mM}$ EDTA was added to the $10 \mu \mathrm{L}$ reactions to stop it, and the Tb885 RNA construct was subsequently ethanol precipitated overnight. Precipitated Tb885 RNA was analyzed on an 8-M urea, wedged $20 \%$ polyacrylamide sequencing gel after resuspension in loading buffer containing $80 \%$ formamide and $0.025 \%$ each of xylene cyanol and bromophenol blue. The Tb885 RNA sample was run alongside a sequencing ladder of RNA partially digested by G-specific RNase $\mathrm{T}_{1}$ and alkaline hydrolysis. Gels were exposed to phosphorimager screens overnight at room temperature, and bands were quantified by using ImageQuant software of a Molecular Dynamics Storm 840 phosphorimager. The relative extent of excision at each nucleotide ( $\Pi$ ) was calculated as described (Harris et al. 2004) from the following equation:

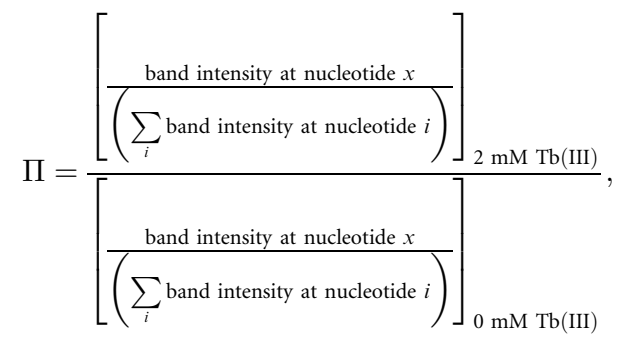

where $x$ is the analyzed nucleotide position in the RNA, and 0 $\mathrm{mM} \mathrm{Tb}(\mathrm{III})$ is the control reaction, described above. Data from the Tb885 constructs were further normalized relative to the value calculated for $\Pi_{\mathrm{C} 899}$, which allowed for comparison of results from different gels. Results were within $5 \%$ error between experiments.

\section{Time-resolved FRET measurements}

RNA construct F885T for FRET experiments was synthesized in a singly fluorescein-labeled form by the Howard Hughes Medical Institute Biopolymer/Keck Foundation Biotechnology Resource Laboratory at the Yale University School of Medicine with the same sequence as construct 885 (5'-GGCGGGGAGUACGGCCGX AAG GUUAAAACYCGCC-3' ${ }^{\prime}$ ), except that the C899 within the GCAA tetraloop and $\mathrm{U} 911$, indicated as $\mathbf{X}$ and $\mathbf{Y}$ respectively, were replaced with Fluorescein dT and Amino-Modifier C6 dT (Glen Research), respectively. The synthetic RNA was deprotected, purified, and subsequently labeled with tetramethylrhodamine succinimidyl ester (Molecular Probes) as previously described (Hoerter et al. 2004).

The global structures of the doubly labeled, conformationally locked $\mathrm{H} 27$ construct F885T were studied as a function of $\mathrm{Mg}^{2+}$ concentration by tr-FRET analysis. The H27 RNA was annealed by heating for $2 \mathrm{~min}$ at $70^{\circ} \mathrm{C}$ and cooling to room temperature over $10 \mathrm{~min}$. The sample was then incubated at $25^{\circ} \mathrm{C}$ for $\geq 5 \mathrm{~min}$ in 50 
$\mathrm{mM}$ Tris- $\mathrm{HCl}\left(\mathrm{pH} \mathrm{7.5)}\right.$ and $50 \mathrm{mM} \mathrm{NH}_{4} \mathrm{Cl}$ with an appropriate $\mathrm{MgCl}_{2}$ concentration prior to collection of time-resolved emission profiles of the donor fluorescein using time-correlated singlephoton counting similar to previously described procedures (Walter et al. 1999; Pereira et al. 2002). To measure donor-acceptor distance distributions, two time-resolved fluorescence decays were collected, with and without the acceptor fluorophore. The fluorescein emission decay in the donor-only complex was used to extract three intrinsic donor lifetimes with their fractional contributions by a sum-of exponentials fit. The data from the doubly labeled complex were then fit with the Förster model for distance distributions, as described (Rueda et al. 2003). The fwhm of the derived distance distributions did not increase by $>10 \%$ over the whole range of $\mathrm{Mg}^{2+}$ concentrations. An additional adjustable fitting parameter that corrects for singly labeled (fluorescein only) RNA was included in these analyses; incomplete acceptor labeling and separation of doubly from singly labeled material combined to give a singly labeled fraction of up to $30 \%$. A control was performed in which the fraction of singly labeled material was intentionally increased by $20 \%$; the singly labeled fraction found in the resulting fit increased accordingly by $20 \%$, as expected. The fits and interfluorophore distances at higher $\mathrm{Mg}^{2+}$ concentrations were not substantially different when the fraction of singly labeled material was fixed to the value found at zero $\mathrm{Mg}^{2+}$ or, alternatively, freely varied.

$\mathrm{Mg}^{2+}$ was titrated by incremental addition of $0.5-\mu \mathrm{L}$ aliquots of appropriate $\mathrm{MgCl}_{2}$ stock solutions, taking into account the volume change; the volume at the end of any given titration increased by not $>8 \%$. Single distance distributions fit well, as judged by the low reduced $\chi^{2}$ values $(<1.3)$ and by evenly distributed residuals. To extract absolute distances, a value of $55 \AA$ was used for the Förster distance, $R_{0}$, of fluorescein and tetramethylrhodamine (Rueda et al. 2003), based on a value of $2 / 3$ for an isotropic orientation factor, which was supported by the high mobility of the fluorophores as evident from their relatively low fluorescence anisotropies $(\sim 0.12$ for fluorescein and $\sim 0.26$ for tetramethylrhodamine) observed in the F885T FRET construct. Mean fluorophore distances were fit with a modified Hill equation as follows:

$$
y=R_{o}+\left[\frac{\left(R_{\max }-R_{o}\right) x^{n}}{x^{n}+M g_{1 / 2}^{n}}\right]
$$

where $M g_{1 / 2}$ is the magnesium half-titration point, $n$ is the Hill coefficient (which was close to unity in both fits indicating lack of cooperativity in metal ion binding), $R_{0}$ is the initial FRET distance at $0 \mathrm{mM} \mathrm{Mg}^{2+}$, and $R_{\max }$ is the FRET distance at saturating magnesium ion concentrations. A similar titration was also performed in an NMR-like phosphate buffer $\left(10 \mathrm{mM} \mathrm{NaP}_{\mathrm{i}}\right.$ at $\mathrm{pH} 7.0$, $50 \mathrm{mM} \mathrm{NaCl}, 0.1 \mathrm{mM}$ EDTA) (data not shown). The $\mathrm{pH}$ had to be raised from 6.4 to 7.0 since fluorescein emission is $\mathrm{pH}$ dependent and the detected signal diminishes as the $\mathrm{pH}$ drops below neutral. Nonetheless, FRET data collected in phosphate buffer gave the same absolute distance changes as did data collected in Tris buffer, although the values were offset by $\sim 0.5 \AA$. Extracted $M g_{1 / 2}$ values for the two data sets were within error of each other.

\section{ACKNOWLEDGMENTS}

We thank Prof. Hashim Al-Hashimi and Dr. Ananya Majumdar for guidance with select NMR experiments, Prof. Erik Zuiderweg for $800-\mathrm{MHz}$ NMR spectrometer time, Dr. Alex Kurochkin for his NMR expertise, Prof. Arthur Pardi for advice on the treatment of NMR data, Jana Sefcikova and Michael Lerner for assistance with H27 electrostatic surface mapping, Dr. David Rueda for guidance in collection of tr-FRET data, and all members of the Walter laboratory and the Michigan RNA Supergroup for helpful discussions. This work was in part supported by NIH grant GM62357, as well as Dow Corning Assistant Professorship and Camille Dreyfus Teacher-Scholar Awards to N.G.W. M.N.L. was supported by an NIH NSRA Postdoctoral Fellowship, and both J.A.H.H. and M.J.B.P. are recipients of NIH Molecular Biophysics Training Grant predoctoral fellowships.

Received April 26, 2005; accepted August 25, 2005.

\section{REFERENCES}

Auffinger, P., Bielecki, L., and Westhof, E. 2004. Symmetric K+ and $\mathrm{Mg} 2+$ ion-binding sites in the 5S rRNA loop E inferred from molecular dynamics simulations. J. Mol. Biol. 335: 555-571.

Ban, N., Nissen, P., Hansen, J., Moore, P.B., and Steitz, T.A. 2000. The complete atomic structure of the large ribosomal subunit at $2.4 \AA$ resolution. Science 289: 905-920.

Belanger, F., Gagnon, M.G., Steinberg, S.V., Cunningham, P.R., and Brakier-Gingras, L. 2004. Study of the functional interaction of the 900 tetraloop of 16 S ribosomal RNA with helix 24 within the bacterial ribosome. J. Mol. Biol. 338: 683-693.

Brodersen, D.E., Clemons Jr., W.M., Carter, A.P., Morgan-Warren, R.J., Wimberly, B.T., and Ramakrishnan, V. 2000. The structural basis for the action of the antibiotics tetracycline, pactamycin, and hygromycin B on the 30 S ribosomal subunit. Cell 103: 11431154.

Cannone, J.J., Subramanian, S., Schnare, M.N., Collett, J.R., D'Souza, L.M., Du, Y., Feng, B., Lin, N., Madabusi, L.V., Muller, K.M., et al. 2002. The comparative RNA Web (CRW) site: An online database of comparative sequence and structure information for ribosomal, intron, and other RNAs. BMC Bioinformatics 3: 2.

Carter, A.P., Clemons, W.M., Brodersen, D.E., Morgan-Warren, R.J., Wimberly, B.T., and Ramakrishnan, V. 2000. Functional insights from the structure of the $30 \mathrm{~S}$ ribosomal subunit and its interactions with antibiotics. Nature 407: 340-348.

Ciesiolka, J., Marciniec, T., and Krzyzosiak, W. 1989. Probing the environment of lanthanide binding sites in yeast tRNA(Phe) by specific metal-ion-promoted cleavages. Eur. J. Biochem. 182: 445450.

Clemons, W.M., Brodersen, D.E., McCutcheon, J.P., May, J.L.C., Carter, A.P., Morgan-Warren, R.J., Wimberly, B.T., and Ramakrishnan, V. 2001. Crystal structure of the $30 \mathrm{~S}$ ribosomal subunit from Thermus thermophilus: Purification, crystallization and structure determination. J. Mol. Biol. 310: 827-843.

Correll, C.C., Freeborn, B., Moore, P.B., and Steitz, T.A. 1997. Metals, motifs, and recognition in the crystal structure of a 5S rRNA domain. Cell 91: 705-712.

Delaglio, F., Grzesiek, S., Vuister, G.W., Zhu, G., Pfeifer, J., and Bax, A. 1995. NMRPipe: A multidimensional spectral processing system based on UNIX pipes. J. Biomol. NMR. 6: 277-293.

DeLano, W. 2002. The PyMOL Molecular Graphics System. DeLano Scientific, San Carlos, CA.

Draper, D.E. 2004. A guide to ions and RNA structure. RNA 10: 335343.

Draper, D.E., Grilley, D., and Soto, A.M. 2005. Ions and RNA folding. Annu. Rev. Biophys. Biomol. Struct. 34: 221-243.

Gdaniec, Z., Sierzputowska-Gracz, H., and Theil, E.C. 1998. Iron regulatory element and internal loop/bulge structure for ferritin mRNA studied by cobalt(III) hexammine binding, molecular modeling, and NMR spectroscopy. Biochemistry 37: 1505-1512. 
Gonzalez Jr., R.L. and Tinoco Jr., I. 1999. Solution structure and thermodynamics of a divalent metal ion binding site in an RNA pseudoknot. J. Mol. Biol. 289: 1267-1282.

Grzesiek, S. and Bax, A. 1993. Measurement of amide proton exchange rates and NOEs with water in $13 \mathrm{C} / 15 \mathrm{~N}$-enriched calcineurin $\mathrm{B}$. J. Biomol. NMR 3: 627-638.

Gutell, R.R., Weiser, B., Woese, C.R., and Noller, H.F. 1985. Comparative anatomy of 16-S-like ribosomal RNA. Prog. Nucleic Acid Res. Mol. Biol. 32: 155-216.

Hargittai, M.R. and Musier-Forsyth, K. 2000. Use of terbium as a probe of tRNA tertiary structure and folding. RNA 6: 1672-1680.

Harris, D.A. and Walter, N.G. 2003. Probing RNA structure and metal-binding sites using terbium footprinting. Curr. Protocols Nucleic Acid Chem. 6.8: 6.8.1-6.8.8.

- 2005. Terbium(III) footprinting as a probe of RNA structure and metal-binding sites. In Handbook of RNA biochemistry (eds. R.K. Hartmann et al.), pp. 205-213. Wiley-VCH, Weinheim.

Harris, D.A., Tinsley, R.A., and Walter, N.G. 2004. Terbiummediated footprinting probes a catalytic conformational switch in the antigenomic hepatitis delta virus ribozyme. J. Mol. Biol. 341: 389-403.

Hermann, T. and Westhof, E. 1998. Exploration of metal ion binding sites in RNA folds by Brownian-dynamics simulations. Structure 6: 1303-1314.

Hoerter, J.A., Lambert, M.N., Pereira, M.J., and Walter, N.G. 2004. Dynamics inherent in helix 27 from Escherichia coli $16 \mathrm{~S}$ ribosomal RNA. Biochemistry 43: 14624-14636.

Jeong, S., Sefcikova, J., Tinsley, R.A., Rueda, D., and Walter NG. 2003. Trans-acting hepatitis $\delta$ virus ribozyme: Catalytic core and global structure are dependent on the $5^{\prime}$ substrate sequence. Biochemistry 42: 7727-7740.

Kieft, J.S. and Tinoco Jr., I. 1997. Solution structure of a metalbinding site in the major groove of RNA complexed with cobalt (III) hexammine. Structure 5: 713-721.

Klein, D.J., Moore, P.B., and Steitz, T.A. 2004. The contribution of metal ions to the structural stability of the large ribosomal subunit. RNA 10: 1366-1379.

Leontis, N.B. and Westhof, E. 1998. A common motif organizes the structure of multi-helix loops in $16 \mathrm{~S}$ and $23 \mathrm{~S}$ ribosomal RNAs. J. Mol. Biol. 283: 571-583.

Lian, L.-Y. and Roberts, C. 1993. Effects of chemical exchange on NMR spectra. In NMR of macromolecules: A practical approach (ed. G.C.K. Roberts), pp. 153-181. Oxford University Press, Oxford, UK.

Lodmell, J.S. and Dahlberg, A.E. 1997. A conformational switch in Escherichia coli $16 \mathrm{~S}$ ribosomal RNA during decoding of messenger RNA. Science 277: 1262-1267.

Lodmell, J.S., Gutell, R.R., and Dahlberg, A.E. 1995. Genetic and comparative analyses reveal an alternative secondary structure in the region of nt 912 of Escherichia coli 16S rRNA. Proc. Natl. Acad. Sci. 92: 10555-10559.

Maderia, M., Horton, T.E., and DeRose, V.J. 2000. Metal interactions with a GAAA RNA tetraloop characterized by (31)P NMR and phosphorothioate substitutions. Biochemistry 39: 81938200.

Manning, G.S. 1978. The molecular theory of polyelectrolyte solutions with applications to the electrostatic properties of polynucleotides. Q. Rev. Biophys. 11: 179-246.

Marion, D., Driscoll, P.C., Kay, L.E., Wingfield, P.T., Bax, A., Gronenborn, A.M., and Clore, G.M. 1989. Overcoming the overlap problem in the assignment of $1 \mathrm{H}$ NMR spectra of larger proteins by use of three-dimensional heteronuclear $1 \mathrm{H}-15 \mathrm{~N}$ Hartmann-Hahnmultiple quantum coherence and nuclear Overhauser-multiple quantum coherence spectroscopy: Application to interleukin 1 beta. Biochemistry 28: 6150-6156.

Matsumura, K. and Komiyama, M. 1997. Enormously fast RNA hydrolysis by lanthanide(III) ions under physiological conditions: Eminent candidates for novel tools of biotechnology. J. Biochem. 122: $387-394$.
Mundoma, C. and Greenbaum, N.L. 2002. Sequestering of Eu(III) by a GAAA RNA tetraloop. J. Am. Chem. Soc. 124: 3525-3532.

Ogle, J.M., Brodersen, D.E., Clemons Jr., W.M., Tarry, M.J., Carter, A.P., and Ramakrishnan, V. 2001. Recognition of cognate transfer RNA by the 30 S ribosomal subunit. Science 292: 897-902.

Ogle, J.M., Murphy, F.V., Tarry, M.J., and Ramakrishnan, V. 2002. Selection of tRNA by the ribosome requires a transition from an open to a closed form. Cell 111: 721-732.

Pereira, M.J., Harris, D.A., Rueda, D., and Walter, N.G. 2002. Reaction pathway of the trans-acting hepatitis delta virus ribozyme: A conformational change accompanies catalysis. Biochemistry 41: 730740.

Peske, F., Savelsbergh, A., Katunin, V.I., Rodnina, M.V., and Wintermeyer, W. 2004. Conformational changes of the small ribosomal subunit during elongation factor G-dependent tRNA-mRNA translocation. J. Mol. Biol. 343: 1183-1194.

Piotto, M., Saudek, V., and Sklenar, V. 1992. Gradient-tailored excitation for single-quantum NMR spectroscopy of aqueous solutions. J. Biomol. NMR 2: 661-665.

Reblova, K., Spackova, N., Koca, J., Leontis, N.B., and Sponer, J. 2004. Long-residency hydration, cation binding, and dynamics of loop E/helix IV rRNA-L25 protein complex. Biophys. J. 87: 33973412.

Rodriguez-Correa, D. and Dahlberg, A.E. 2004. Genetic evidence against the $16 \mathrm{~S}$ ribosomal RNA helix 27 conformational switch model. RNA 10: 28-33.

Rudisser, S. and Tinoco Jr., I. 2000. Solution structure of cobalt(III)hexammine complexed to the GAAA tetraloop, and metal-ion binding to G.A mismatches. J. Mol. Biol. 295: 1211-1223.

Rueda, D., Wick, K., McDowell, S.E., and Walter, N.G. 2003. Diffusely bound $\mathrm{Mg} 2+$ ions slightly reorient stems I and II of the hammerhead ribozyme to increase the probability of formation of the catalytic core. Biochemistry 42: 9924-9936.

Schluenzen, F., Tocilj, A., Zarivach, R., Harms, J., Gluehmann, M., Janell, D., Bashan, A., Bartels, H., Agmon, I., Franceschi, F., et al. 2000. Structure of functionally activated small ribosomal subunit at $3.3 \AA$ resolution. Cell 102: 615-623.

Serra, M.J., Baird, J.D., Dale, T., and Fey, B.L. 2002. Effects of magnesium ions on the stabilization of RNA oligomers of defined structures. RNA 8: 307-323.

Sigel, R.K. and Pyle, A.M. 2003. Lanthanide ions as probes for metal ions in the structure and catalytic mechanism of ribozymes. Met. Ions Biol. Syst. 40: 477-512.

Szewczak, A.A. and Moore, P.B. 1995. The sarcin/ricin loop, a modular RNA. J. Mol. Biol. 247: 81-98.

Tama, F., Valle, M., Frank, J., and Brooks III, C.L. 2003. Dynamic reorganization of the functionally active ribosome explored by normal mode analysis and cryo-electron microscopy. Proc. Natl. Acad. Sci. 100: 9319-9323.

Tanaka, Y. and Taira, K. 2005. Detection of RNA nucleobase metalation by NMR spectroscopy. Chem. Commun. (Camb.) 16: 20692079.

Tinsley, R.A., Harris, D.A., and Walter, N.G. 2004. Magnesium dependence of the amplified conformational switch in the trans-acting hepatitis delta virus ribozyme. Biochemistry 43: 8935-8945.

Varani, G., Aboul-ela, F., and Allain, F.-T. 1996. NMR investigation of RNA structure. Progr. Nuclear Magn. Reson. Spectr. 29: 51-127.

Vila-Sanjurjo, A., Ridgeway, W.K., Seymaner, V., Zhang, W., Santoso, S., Yu, K., and Cate, J.H. 2003. X-ray crystal structures of the WT and a hyper-accurate ribosome from Escherichia coli. Proc. Natl. Acad. Sci. 100: 8682-8687.

Walter, N.G., Burke, J.M., and Millar, D.P. 1999. Stability of hairpin ribozyme tertiary structure is governed by the interdomain junction. Nat. Struct. Biol. 6: 544-549.

Walter, N.G., Yang, N., and Burke, J.M. 2000. Probing non-selective cation binding in the hairpin ribozyme with $\mathrm{Tb}(\mathrm{III})$. J. Mol. Biol. 298: $539-555$. 


\section{Lambert et al.}

Wedekind, J.E. and McKay, D.B. 2003. Crystal structure of the leadzyme at 1.8 angstrom resolution: Metal ion binding and the implications for catalytic mechanism and allo site ion regulation. Biochemistry 42: 9554-9563.

Wijmenga, S., Mooren, M., and Hilbers, C. 1993. NMR of nucleic acids: From spectrum to structure. In NMR of macromolecules: $A$ practical approach (ed. G.C.K. Roberts), pp. 217-288. Oxford University Press, Oxford, UK.
Wimberly, B.T., Brodersen, D.E., Clemons Jr., W.M., Morgan-Warren, R.J., Carter, A.P., Vonrhein, C., Hartsch, T., and Ramakrishnan, V. 2000. Structure of the 30S ribosomal subunit. Nature 407: 327-339. Woodson, S.A. 2005. Metal ions and RNA folding: A highly charged topic with a dynamic future. Curr. Opin. Chem. Biol. 9: 104-109. Yusupov, M.M., Yusupova, G.Z., Baucom, A., Lieberman, K., Earnest, T.N., Cate, J.H., and Noller, H.F. 2001. Crystal structure of the ribosome at $5.5 \AA$ A resolution. Science 292: $883-896$. 

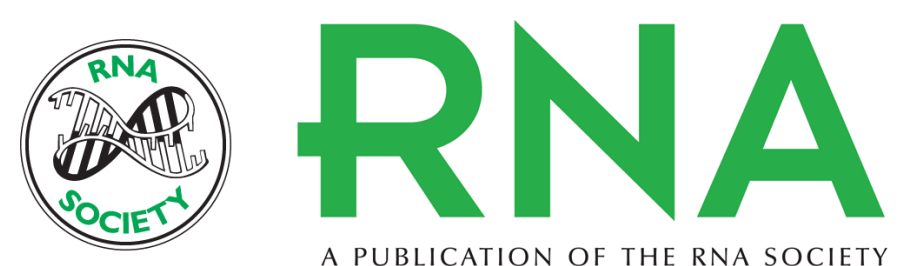

A PUBLICATION OF THE RNA SOCIETY

\section{Solution probing of metal ion binding by helix 27 from Escherichia coli 16S rRNA}

MEREDITH NEWBY LAMBERT, JOHN A.H. HOERTER, MIGUEL J.B. PEREIRA, et al.

RNA 2005 11: 1688-1700

References This article cites 54 articles, 12 of which can be accessed free at: http://rnajournal.cshlp.org/content/11/11/1688.full.html\#ref-list-1

\section{License}

Email Alerting Receive free email alerts when new articles cite this article - sign up in the box at the top Service right corner of the article or click here. 